\title{
Exploration and Practical Research on the Integration of Modeling Thought into Economics Teaching in Colleges and Universities
}

\author{
Xinyun Tang \\ School of Economics, Anhui University of Finance and Economics, Bengbu, Anhui, China
}

\begin{abstract}
How to make students apply their theoretical knowledge to practice and complete the teaching objectives of macro and micro economics through economics teaching reform is a common concern of teachers majoring in economic management in many colleges and universities. Starting from the necessity and significance of modeling thought in economics teaching, this paper demonstrates the practical application of mathematical modeling in economics teaching, and puts forward the way of integrating modeling thought into economics teaching in Colleges and universities.
\end{abstract}

Keywords: Modeling idea, Integration, Economics Teaching.

\section{Introduction}

Macroeconomics and microeconomics is a core course of economic management approved by the Ministry of education. It is a professional basic course of economics and management. It has been highly valued in the teaching process of colleges and universities. How to make students apply their theoretical knowledge to practice and complete the teaching objectives of macro and micro economics through economic teaching reform is a common concern of teachers majoring in economic management in many colleges and universities. Ruan Shouwu (2009) believes that the key to economics teaching is to let students master the basic principles and methods of economics, look at the development of economics from the perspective of methodology, and help students establish the thinking mode of Economics [1]. Li Gui'e (2010) proposed to learn from the research teaching experience of Cambridge University, take the innovative teaching concept as the guidance, take the problem as the guidance, and carry out research teaching from two aspects of classroom teaching and extracurricular guidance, which plays a significant role in cultivating students' innovative consciousness [2]. Cao Jianzhong (2011) believed that the goal of microeconomics teaching reform should be to cultivate students' learning interest, help students establish economic thinking mode and improve students' ability to analyze practical problems [3].

Mathematical modeling was introduced into the classrooms of Fudan University and China University of science and technology in the early 1980s. Since the working conference of "National College Students' mathematical modeling competition" was held in 1996, colleges and universities across the country have set off an upsurge of mathematical modeling. As one of the tools that can effectively improve students' practical and innovative thinking ability, modeling idea has attracted more and more attention of college teachers. Therefore, how to infiltrate the idea of modeling into mathematics teaching has become a research hotspot of Chinese scholars, and the results are fruitful. However, there are also a large number of mathematical models in macroeconomics and microeconomics. Chinese scholars' research on how to integrate modeling ideas into economics teaching in Colleges and universities is slightly insufficient. Practice has proved that the economic model has played a great role in cultivating students' observation, imagination, logical thinking ability and the ability to analyze and solve problems. By studying how to integrate the modeling idea into the economics teaching in Colleges and universities, effectively integrate the economic theoretical knowledge and modeling idea, guide students to integrate theory with practice, and improve their ability to analyze and solve practical economic problems, which has important theoretical and practical significance for colleges and universities in China to better complete the macro and microeconomic teaching objectives.

\section{The Necessity of Integrating Modeling Ideas into Economics Teaching in Colleges and Universities}

\subsection{Problems in Current Economics Teaching in Colleges and Universities}

(1) There is a lack of cultivation of students' economic thinking. As students of economics, in addition to mastering the principles of economics, it is more important to have an economic thinking mode. However, compared with some subjects, the knowledge of economics is more theoretical, the principles and knowledge points are profound, and it is difficult for beginners to understand. Most teachers pay attention to the inheritance of knowledge and provide students with case study. There is a lack of opportunities for exploratory learning, ignoring the cultivation of students' economic logical thinking.

(2) Traditional teaching methods. In reality, the teaching methods of economics are generally single and boring, "teaching acceptance". To a certain extent, type teaching still occupies a dominant position, and there is less communication and interaction between teachers and students in the classroom, which will inevitably lead to the difficulty in improving the teaching quality and teaching effect. Although the traditional teaching mode enables students to obtain temporary understanding and memory, it lacks the training for students to think independently and solve 
practical problems with economic models, resulting in the rigidity of students' knowledge absorption.

(3) Lack of modeling cases in teaching. Economics is a social discipline with strong application. The teaching method based on theoretical teaching makes students still can't use these theories to analyze practical problems after learning theories. In practical teaching, teachers mostly simply apply classic cases and ignore the guidance of modeling cases.

\subsection{The Significance of Integrating Modeling Thought into Economics Teaching in Colleges and Universities}

(1) It is conducive to further deepening the reform of Economics Teaching in Colleges and universities. In reality, the teaching methods of economics are generally single and boring, and the indoctrination teaching still occupies a leading position to a certain extent. In the current economics teaching objectives, it is difficult to achieve the planned teaching contents in the traditional economics teaching methods, but if in the teaching process. This problem can be solved by effectively integrating the idea of modeling into economics teaching, so as to promote the substantive completion of the teaching goal of economics. It can be seen that the integration of modeling thought into economics teaching in Colleges and universities is the need of the teaching goal of economics course itself, which is conducive to promoting the further reform of economics teaching in Colleges and universities.

(2) It is conducive to promoting the cultivation of Applied Talents in economics in Colleges and universities. In economics teaching, because the knowledge of economics is more theoretical than some subjects, the principle is profound and difficult to understand, students are easy to show a negative attitude in learning. Introducing the idea of modeling into economics teaching and focusing on cultivating the ability of applied undergraduate talents to analyze and solve problems can promote learning Students' ability to apply economic knowledge has been greatly improved in the specific modeling process. At the same time, in the process of modeling, students need to independently consult relevant literature, read and digest in time, and apply it to modeling, which can improve students' ability to acquire new knowledge to solve complex problems, which is conducive to the cultivation of Applied Talents in economics in Colleges and universities.

(3) It is conducive to stimulate students' interest in learning and cultivate students' innovative ability. In the process of economics teaching, teachers pay more attention to the explanation of theories and exercises in content processing, which often affects students' interest in learning because of monotonous content. The construction of economic model can improve students' low initiative and enthusiasm in economics learning. The problems solved by the type come from real life, and the problems raised are easy to arouse the interest of students. At the same time, modeling thinking has great flexibility and the results are not unique. Students can establish corresponding models from different angles to solve practical problems, which is conducive to the cultivation of students' innovative ability.

\section{Application of Mathematical Modeling in Economics Teaching}

In today's college teaching, it can be said that there is a close relationship between mathematical modeling and economics. Any economic research and calculation is inseparable from the establishment of mathematical model. Using mathematical model to assist the development of economics can more intuitively let people see the economic development situation. For example, in the macro-control and price control of economics, there is the integration of mathematical modeling. The use of mathematical modeling can contribute to the macroeconomic analysis of economic experiments. In some experiments and price control, mathematical problems are often involved. In the experimental design of mathematical statistics in microeconomics, it reflects the promoting role of mathematical modeling in economics. Next, the author will make a specific analysis of the important role of mathematical modeling in economics.

\subsection{The Importance of Mathematical Economic Model for Economic Research}

The advantage of an economic model is to use refined logic to derive conclusions under given assumptions. This avoids the uncertainty of speech derivation and increases the basis for discussion. If you do not agree with the conclusion, you can directly return to the hypothesis. Only on this basis can economics develop rapidly in recent years. Therefore, strictly speaking, contemporary economics began with Samuelson. He was the first to attribute economics to optimization problems under constraints - this is a mathematical model.

As a social science, the primary purpose of economics is to understand reality, and the benefits of mathematical modeling are significant. For example, in the early various auction forms, it is difficult for ordinary people to know their advantages and disadvantages. However, after introducing the mathematical model, we know that the expected returns of the original several main auction methods are the same. Another example is the famous adverse selection problem in economics, which is also found through a simple mathematical model. Many times, a simple theory is often an abnormal thinking. For example, ordinary people generally have the opposite perception of comparative advantage. However, a simple model can show that the trade brought by comparative advantage is beneficial to both sides.

From the perspective of application, economic models are also helpful. For example, search theory is widely used in price behavior and industrial organization in corporate governance. Generally speaking, the development of micro theory is relatively mature, and there are many identification and practical applications of mathematical models. Some simplified models are prepared for complex analysis.

In general, relying on mathematical models alone is not enough to solve all economic problems. Many problems in economic fields need detailed analysis from a micro perspective to summarize the laws. If we want to use mathematical knowledge to solve the problems in economics, we must establish an appropriate economic model. It is not unreasonable to use mathematical modeling to solve problems in economics. Most of the time, we can only know the direction and purpose of the problem from the perspective of economics. As for the process, we can't have a detailed analysis, but we can completely solve this problem by using mathematical model. Mathematical modeling can more truly reflect the actual situation of existing economy in the form of digital, image and block diagram. 


\subsection{General Steps of Constructing Economic Mathematical Model}

In order to use mathematical models to better solve the existing economic problems, it is mainly divided into two steps. First, we should distinguish the background of the problem and be familiar with the problem, then improve the existing economic problems in the form of assumptions, and construct some reasonable mathematical models in an abstract and visual way. Use mathematical knowledge and skills to describe the relationship between variables and parameters in the problem. In this way, we can get some economic data, and then compare and analyze the data obtained in the modeling with the actual situation, and finally get the results

\subsection{Application Examples}

Mathematical model of commodity price increase:

(1) Problem. Nowadays, economics is used in many shopping malls. For example, in order to obtain the maximum economic benefits of the same goods, we should consider both the specified price and the sales quantity. If the price is too low, the sales quantity will be more. If the price is high, the profit will be large, but the sales quantity will be affected. How to price can it lack of economic efficiency. The maximization of benefits has become an important issue to be considered. This involves the relationship between mathematical modeling and economic benefits. Through drawing, we can find out how to price so as to maximize the marginal effect of goods.

(2) Example analysis. For example, when a shopping mall sells a commodity, the price of a single product is set to 30 yuan, and the average sales volume is 20000 pieces per year. If the price of a commodity is increased by 1 yuan, the sales volume will be reduced by 20000 . If the total sales revenue is not less than 700000 , how should the maximum price of the commodity be priced? For such a problem, we can use mathematical thinking to calculate, false If the price increase is $\mathrm{X}$ Yuan and the unit price of the commodity after the price increase is $30+\mathrm{X}$ Yuan, the total sales volume after the price increase is $(20000-2000 \mathrm{x} / 1)$, then it can be concluded that $(30+x)(30000-2000 x / 1)$ is greater than or equal to 700000 , so that we can accurately calculate how to formulate the maximum pricing.

\subsection{Limitations of the application of mathematics in Economics}

(1) Economics is not a simple collection of mathematical concepts and models. The application of mathematics in economy has certain limitations. The use of mathematical knowledge and mathematical models to solve some phenomena in economics is not an extension and exploration of mathematics, but the use of mathematics to more conveniently explain some phenomena in economics. Economics as a social science Branch discipline has become an important discipline for human social development and scientific progress, and human beings are gradually dependent on Economics under the influence of activities and morality. The development of economics cannot become an abstract science that can be calculated directly by formulas. Only by integrating mathematical knowledge and mathematical models can it better assist the development of Economics [4].

(2) The development of economic theory needs to start from its own unique research perspective. In the development of economic theory, it is often necessary to observe from its own unique research perspective to find that the use of mathematical models to assist the analysis and research of economics has an important impact, but the application of mathematical modeling is not unconditionally applicable to any place, but has a certain significance In the field of economics, the application of mathematical modeling has a specific field, and it is not unrestrained and can be applied to any field.

(3) Mathematical econometric analysis is only one of the tools to assist economic theory. Using mathematical modeling to solve the existing economic problems is a common way, but this method is not omnipotent. Because many economic problems can not be solved completely by mathematical modeling, teachers in Colleges and universities still need to use the thinking mode of economics solve. Therefore, in order to better promote the education and development of economics, it must be properly integrated with mathematical modeling, which will be conducive to the development of economics.

(4) Mathematical economic modeling is widely used. The use of mathematical modeling has played a great role in economics. For example, many enterprises or departments now determine how to formulate regulations and systems by calculating the relationship between economic benefits and costs in order to save their own expenses. It is expected that the development of economics will continue in the next few years. It will have a good prospect, and the application of mathematical modeling in economics will be better developed. Rational use of mathematical modeling can greatly promote the research and development of economics, which is not only the direction that China should strive for in the future, but also the direction that China needs to continue in-depth research and development [5].

To sum up, the author briefly discusses the application of mathematical modeling in economics. Through analysis, it can be found that China's economic development has been extended to a certain extent. Whether from the perspective of macro-economic benefits or micro-economic benefits, the development of economics needs to be assisted by appropriate mathematical modeling. In recent years, the use of mathematical modeling has made great contributions to China's economic take-off and economic development.

\section{Ways of Integrating Modeling Ideas into Economics Teaching in Colleges and Universities}

The purpose of integrating modeling into economics teaching in Colleges and universities is to urge students to learn to use mathematical models and economic models to refine real economic problems, and then use models to solve problems. The content of modeling ideological system is to train students to express the actual problems in economic language through analysis and reasoning, put forward a series of assumptions in line with the actual background of the problem, establish the corresponding economic model, and then seek appropriate solutions

Quantity tools to obtain the results of the model. Finally, the results of the model need to be expressed in popular language to solve practical problems. The specific ways are as follows: the first step is to put forward practical problems. Combined with daily life, ask questions about the economic 
phenomena in life. The second step is refining and abstracting. This step is to refine and simplify practical problems and abstract them into economic terms. At the same time, collect necessary information, clarify the characteristics of the object, and find out the corresponding economic theory. The third step is to form model assumptions. After integrating the problem into economic theory, we need to put forward a series of assumptions in line with the actual background of the problem, so as to pave the way for establishing the corresponding economic model. The fourth step is to establish the model. Based on the model assumptions, establish relevant economic models, explain the model principles, quantify the problems, and use mathematical models to refine and abstract the real economic problems into mathematical problems. The fifth step is to solve the model. Solve the model and get the solution. The traditional methods of solving equations, drawing and proving can be used, and econometric software can also be used. Step 6: after the results obtained from the above process, explain and explain the results in combination with practical problems, and finally solve the questions [6].

At the same time, when training students to establish modeling ideas in the teaching process, we also need to pay attention to the following points.

First, the expression of economic terms is colloquial. In the initial teaching stage, due to the strong theoretical knowledge of economics, profound principles and difficult to understand, students will feel boring, easy to show a negative attitude and low learning enthusiasm. Therefore, in the face of students who are beginning to learn economics, we should first guide students to understand the concept of economics in their touchable daily life, and interpret various concepts of economics in life language, so that students feel that the concepts in the textbook are not boring, but related to life interest. For example, for the concepts of price elasticity, opportunity cost, economic profit and moral hazard in economics, teachers need to explain them in easy to understand language and equipped with specific and vivid examples, which can not only stimulate students' interest in learning, but also deepen students' understanding of basic concepts, so as to receive better teaching results.

Second, the promotion of case teaching is deepened. The essence of integrating modeling ideas is to integrate with practice. Therefore, in the process of Economics Teaching in Colleges and universities, we do not only occasionally insert a few examples in the course of lectures, but run the teaching principle of integrating practice through the whole process of economics teaching. We should try to combine with reality, design appropriate problem situations, guide students to participate in teaching activities, and let students experience that they can solve practical economic problems through their own thinking. Therefore, in classroom teaching, take specific cases as the teaching content, and introduce the ideas and methods of modeling through the modeling examples of specific problems. At the same time, the selected examples should be close to the content of teaching materials, students' cognitive level and the reality of real life. The expertise involved should not be too much and should be easy to understand. The focus of this stage is to stand at the height of improving students' quality, take the awareness of infiltration modeling as the primary task through joint discussion between teachers and students, and pay attention to cultivating students' reading comprehension ability and the ability to apply models to solve practical problems. For example, in 2015, China's stock market soared and plummeted many times, the central bank lowered reserve requirements and interest rates many times, and spared no effort to protect the market. These economic cases in reality are close to students' cognitive level and students' life reality. If this case is explained to students in combination with relevant knowledge such as monetary policy, financial policy and IS-LM model in economics teaching. It will stimulate students' enthusiasm for discussion, so as to cultivate students' ability to analyze and solve problems.

The third is the daily use of modeling tools. The process of solving economic model is generally cumbersome, which requires strong mathematical skills and familiar with the application principle of the model. With the continuous advancement of teaching reform, modern teaching aids are also constantly entering the classroom. From the traditional blackboard to the projector more than ten years ago, and then to the current multimedia, the application of these modern instruments has brought great convenience to modern teaching. Therefore, teachers should make full use of these auxiliary facilities to improve their teaching quality. In particular, the popularity of computers has brought a lot of convenience to the solution of economic models. If teachers can make good use of measurement software, teaching can achieve twice the result with half the effort. At the same time, teachers should guide students to strengthen after-school practice and improve their familiarity with the software. After class practice is an important part of cultivating students' ability to use measurement software. When designing after class exercises, we should choose some practical problems that are suitable for beginners to operate better, so that students can not only master theoretical knowledge, but also obtain the ability to use computers to solve practical problems.

\section{Contents to be Further Studied}

The high abstraction of mathematics ensures its universality. For example, an apple and a Durian are treated with a number 1 in mathematics. The theory studied is very universal, such as $1 / 2=0.5$. If you cut any fruit, it is half. But the main contradiction of mathematics is that when a theory rises to a certain height, its application becomes more difficult. For example, we often say: do you use trigonometric functions to buy vegetables?

However, in economics with a low degree of abstraction, apple and durian are two very different commodities, which are embodied in different producing areas, different transportation costs, the availability of substitutes and so on. This makes it difficult to draw an economic principle with universal value. For example, the principle of monopoly not only limits several monopolies, but also limits the nature of monopoly goods, whether there is collusion or cooperation, etc. However, once the conclusion is drawn, its application is very directional, such as cartel and OPEC.

On the one hand, highly abstract mathematical theorems can be widely used in physics, so that physics can be used as a springboard to practice. For example, the integral method can calculate the field strength of charged geometry. The fundamental reason for its feasibility is that physics itself has medium abstraction and medium practical operability. In vernacular, physics pays more attention to an apple than mathematics, such as 200 grams of an apple; But it pays less attention than the economy. For example, it doesn't have to know that this apple is produced in Fujian.

On the other hand, although mathematical models can also 
be applied to economic principles, due to the limitations of economic principles, a mathematical model can only correspond to the analysis of a few market conditions. In this case, the mathematical model is still accurate, but it has lost its original universal value because of the limitations brought by its application to economics.

\section{Conclusion}

Macroeconomics and microeconomics is the core course of economic management approved by the Ministry of education, which has been highly valued in the teaching process of colleges and universities. At present, there are some disadvantages in the teaching of economics in Colleges and universities, such as the teaching of theoretical knowledge is more important than the cultivation of thinking ability, traditional teaching methods and so on, which lead to the solidification of knowledge, so that students can not apply the learned theoretical knowledge to practice. As one of the tools that can effectively improve students' practical and innovative thinking ability, modeling idea has attracted more and more attention in college teaching. The fundamental of integrating modeling into economics teaching in Colleges and universities is to urge students to learn to use mathematical models to refine and abstract real economic problems into mathematical problems, and then answer them. When students encounter actual economic problems, they should first express the actual problems in economic language through analysis and reasoning, put forward a series of assumptions in line with the actual background of the problem, establish the corresponding economic model, then seek appropriate measurement tools to obtain the results of the model, and finally express the results of the model in popular language, It is used to solve practical problems and form a modeling ideological system. In addition, in order to effectively integrate the modeling idea into the teaching of economics in Colleges and universities, teachers should pay attention to the colloquial expression of economic terms, the in-depth promotion of case teaching, and the daily use of modeling tools, so as to further deepen the reform of Economics Teaching in Colleges and universities, promote the cultivation of applied talents in economics in Colleges and universities and the improvement of students' innovation ability.

\section{References}

[1] Ruan Shouwu. Understanding of modern economics and teaching of "western economics" [J]. China University teaching, 2009 (10): 44-45.

[2] Li gui'e. Application of research teaching in the teaching of regional economics $[\mathrm{J}]$. Higher education research, 2010,31(06):90-92.

[3] Cao Jianzhong. Exploration in experiment and innovation in exploration -- one of the exploration of the experimental teaching mode of "optimizing the teaching process by using modern educational technology" [J]. Educational Research Forum, 2011(01):87-88.

[4] Li Haixia. Practical exploration of the "five moves" teaching mode of Higher Mathematics in Higher Vocational Colleges Based on the idea of mathematical modeling [J]. mathematics learning and research, 2020 (1): 117-118.

[5] Tang Aiwen. On how to cultivate the core quality of Mathematics: "element" in design and "cultivation" in class -Taking "sinusoidal function image and simple property using modeling idea teaching design" as an example [J]. Middle school mathematics, 2020 (5): 35-37.

[6] Lin Jin. From "starting with problems" to "deep application" -strategies for cultivating modeling ideas in primary school mathematics classroom [J]. New teacher, 2020 (2): 45-46. 